\title{
Management of cognition as reported in Japanese historical documents and modern anesthesiology research papers
}

\author{
Shigeru Saito ${ }^{1} \mathbb{D}$
}

Received: 20 June 2016 / Accepted: 14 July 2016 / Published online: 20 July 2016

(C) Japanese Society of Anesthesiologists 2016

\section{Management of cognition in anesthesiology}

From the time anesthesia was established as a medical specialty, the main duty of the anesthesiologist during the perioperative period has been the management of consciousness. Most patients prefer to be unconscious during stressful and painful experiences, such as surgery and wound treatment, and anesthesiologists play a key role in controlling the patient's awareness in these situations. With expansion of the anesthesiologist's duties, they are now responsible for the pre- and postoperative mental status of the patient and a smooth return to their daily life. In such a social environment, anesthesiologists inevitably have to focus more on cognition, rather than consciousness.

\section{Definition of cognition}

Consciousness is defined as "awareness of an external object or something within oneself", and cognition is defined as "the mental process of acquiring knowledge and coordinating attention, memory, judgment and evaluation" [1]. Cognition includes reasoning, problem solving and decision-making. Cognition is a more complicated process compared to simple consciousness. Adequate cognition is indispensable to secure a safe transition from hospital stay to a return to daily pre-admission life; this faculty is

Shigeru Saito

shigerus@gunma-u.ac.jp

1 Department of Anesthesiology, Gunma University Graduate School of Medicine, 3-39-22, Showa-machi, Maebashi 371-8511, Japan imperative for patients and their family members, especially in aged societies, such as Japan.

In modern cognitive psychology and cognitive engineering, cognition is typically assumed to be information processing in the participant's or operator's mind or brain [2]. Obviously, modification of and interference with cognitive processes influences the person's mental status and behavior. The importance of proper cognition in various social environments and the ability to control cognition has been recognized throughout human history. Several old oriental literatures, for example, have reported that cognition can be influenced and controlled by multiple factors-"Clear your mind of all mundane thoughts, and you will find even fire cool" according to the Japanese priest Kaisen Joki (15021582) (Fig. 1), and "If you have established your own philosophy, nothing will trouble you as if you would feel fire cool" by the Chinese poet To Junkaku (846-904) [3]. Both express the notion that physical sensations including pain and temperature can be cognitively controlled.

\section{Management of cognition in Japanese history}

Since proper cognition is important for correct understanding of one's surroundings and for adequate decision making, and can be influenced by multiple factors, active management of this neurological function can be utilized for intentional control of one's physical and/or mental condition, and disturbing the understanding or altering the behavior of others. Cognitive behavioral therapy in chronic pain management incorporates this brain function as part of the therapeutic regimen [4]. Zen meditation in Buddhism utilizes cognitive activities for mental peacefulness (Fig. 2) [5]. The 'Ninja', who were intelligence operatives and spies during the Japanese medieval 'Samurai' era, strategically utilized 
Fig. 1 Wooden gate 'Sanmon' of Erinji temple (Enzan, Japan). The Chinese 'Kanji' characters written on the gate read: clear your mind of all mundane thoughts, and you will find even fire cool

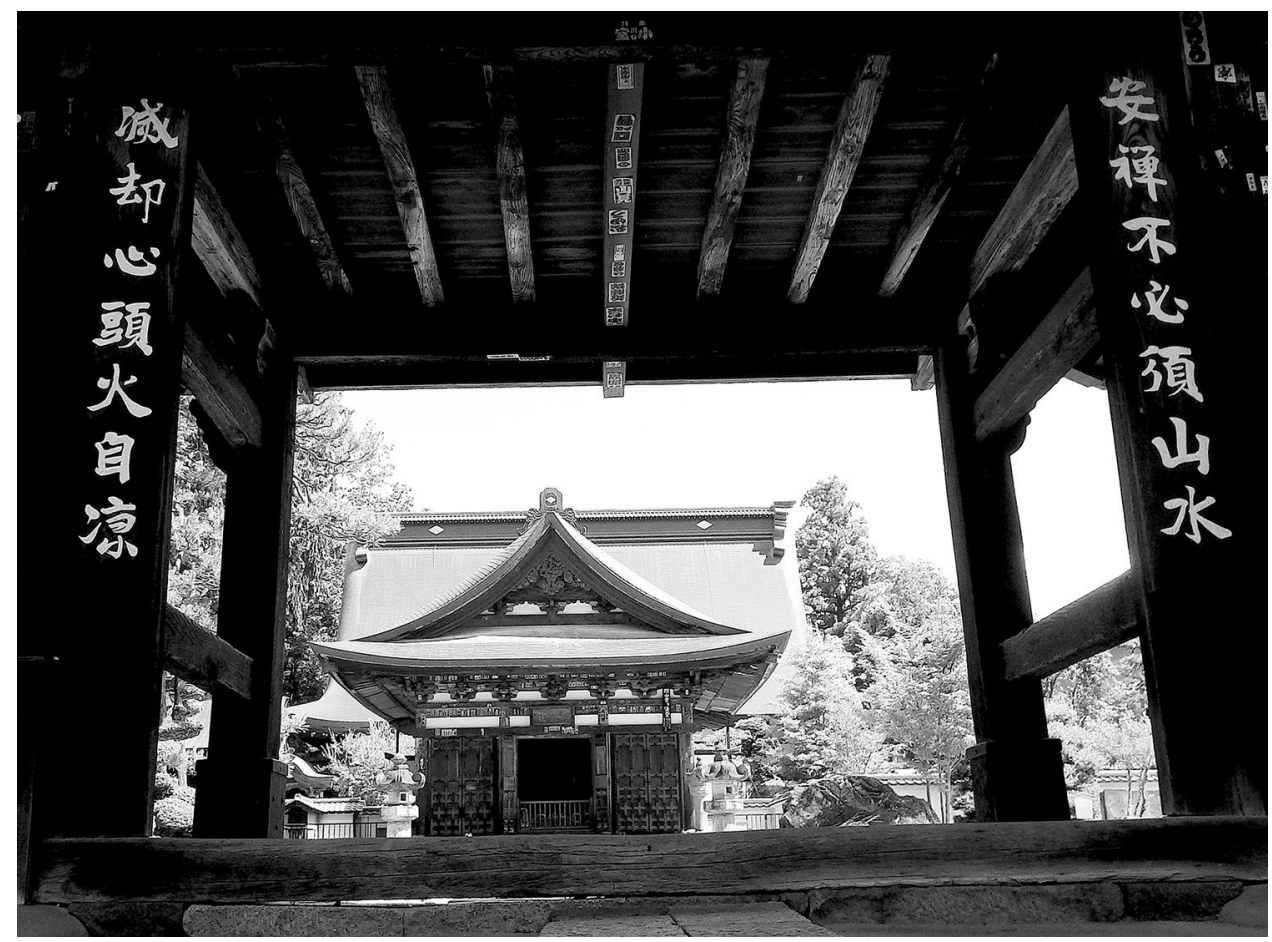

several types of psychological interventions against their enemies to disturb their opponents' teamwork (Fig. 3) [6]. From these examples, it is easily realized that cognition is more complicated than simple consciousness, and that correct cognition is essential for safe and peaceful daily living.

\section{Current understanding of postoperative cognitive dysfunction (POCD)}

In many surgical cases it is recognized that cognition seems to decline after surgery. Postoperative delirium, manifested as hyperactivity, is easily recognized; however, cognitive dysfunction is not clinically apparent in many cases and can only be detected by neuropsychological tests. Since the causes for these two neurological dysfunctions are not fully understood, discriminating between them is still controversial. In most cases, cognitive decline might be solely noticed by the patient or relatives while the patient is still in the hospital. However, it is possible that subtle dysfunctions may remain unnoticed until the patient returns home and tries to resume their daily life. Insufficient memory is common, and uncoordinated information processing can be troublesome at work and home. Although these are categorized as 'clinically minor complications', they are capable of interfering with the life of a patient postoperatively. Cognitive dysfunction does not lead to the patient showing physical dysfunction or becoming bedridden, as seen after a stroke. However, the extremely high incidence of POCD compared to stroke makes this condition highly problematic, especially in terms of social impact, such as quality of life of an aged population and economic burden on healthcare resources [7].

There is wide variation among the reported rates of $\operatorname{cog}$ nitive dysfunction after major surgery. In the immediate postoperative period, the incidence is as high as $80-90 \%$, which means that almost all patients experience cognitive abnormalities after major surgery [7]. Rudolph and Marcantonio reported that the rate of postoperative delirium ranges from $5 \%$ to approximately $50 \%$, depending on the type of surgery [8]. Moller et al. reported that approximately $25 \%$ of elderly patients exhibit cognitive deterioration for one week after non-cardiac procedures and $10 \%$ exhibit dysfunction for 3 months after major surgery under general anesthesia [9]. However, several months after surgery, the incidence decreases to less than half of the patients, and at one year after surgery, decreases to approximately one-quarter of patients. Although it may be true that most of the early cognitive loss is transient, multiple longitudinal studies demonstrated that, in some cases, it persists for several years after surgery $[10,11]$.

\section{Risk factors and proposed mechanisms of cognitive dysfunction}

The typical risk factors and etiology of POCD include cardiopulmonary bypass, hypoxemia, hypotension, inflammation and stress, and neurotoxicity due to anesthetics, etc [7]. POCD is more frequent after cardiac surgery than 
Fig. 2 A Zen meditation text: 'tendai shoshikan' originally written in the 7 th century. The written message means: mental status influences the physical condition in many ways. Adapted from the 1877 version stored in the Japanese National Diet Library

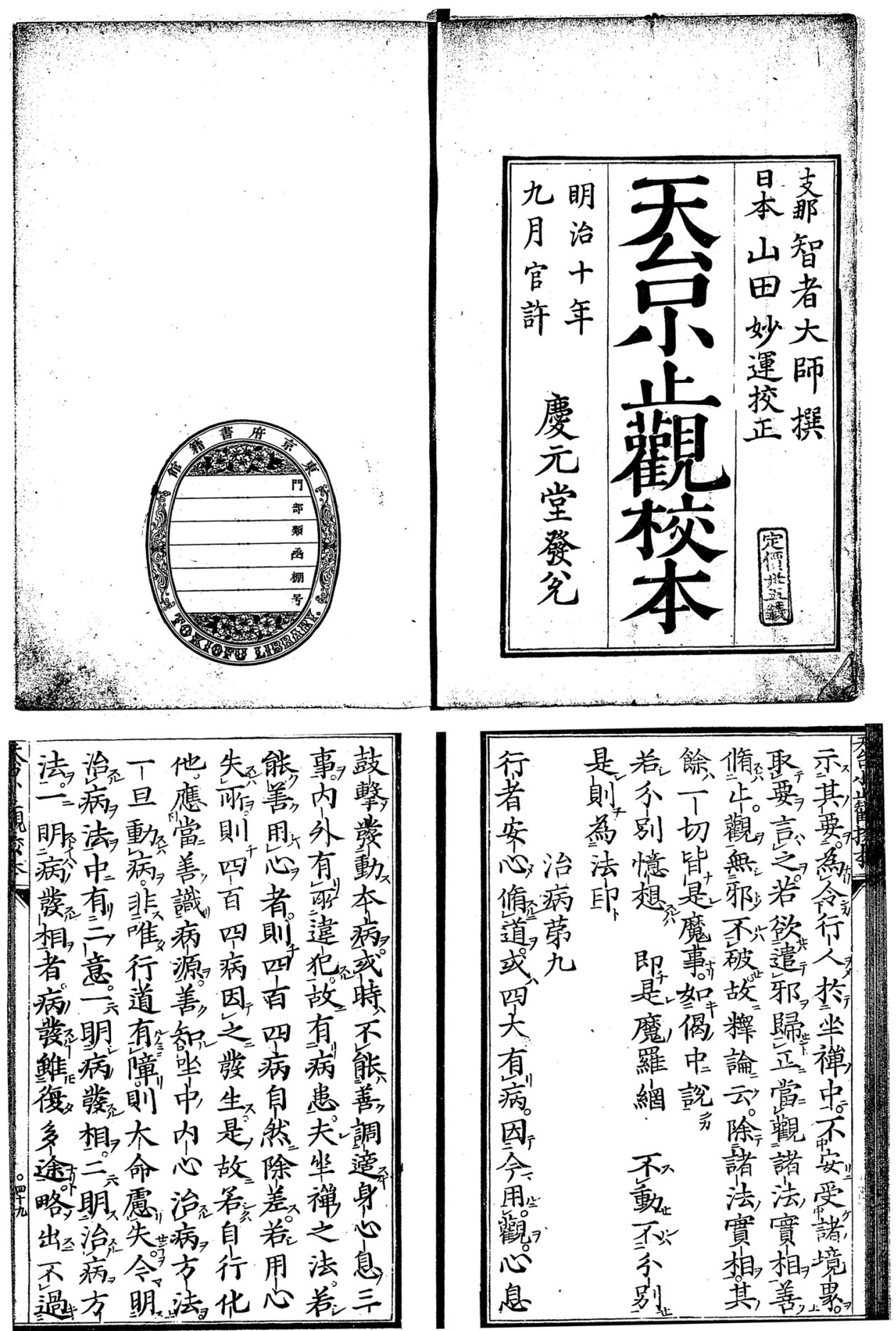

non-cardiac surgery. Many previous studies demonstrated that this complication is associated with the duration of cardiopulmonary bypass, valve surgery and impaired cardiac function. Embolization of particulate and gaseous material into the cerebral microvasculature, resulting in focal areas of cerebral ischemia, has been best studied as the mechanism underlying cognitive dysfunction following cardiac and orthopedic surgeries [11, 12]. However, it is still controversial whether cerebral embolization is the cause of such cardiac surgery-related cognitive impairment, since, in some studies, the rates of cognitive dysfunction were similar even after coronary artery bypass surgery without cardiopulmonary bypass [13]. Other mechanisms distinct from embolization have also been proposed to explain cognitive dysfunction. Reportedly, cerebral and systemic inflammatory effects can be induced by cardiopulmonary bypass 
Fig. 3 A Ninja text: 'Sho-ninki' written in 1681 . This part of the Ninja text says that an opponent's cognition can be controlled by saying something beneficial and enticing to them. Adapted from reference [6]

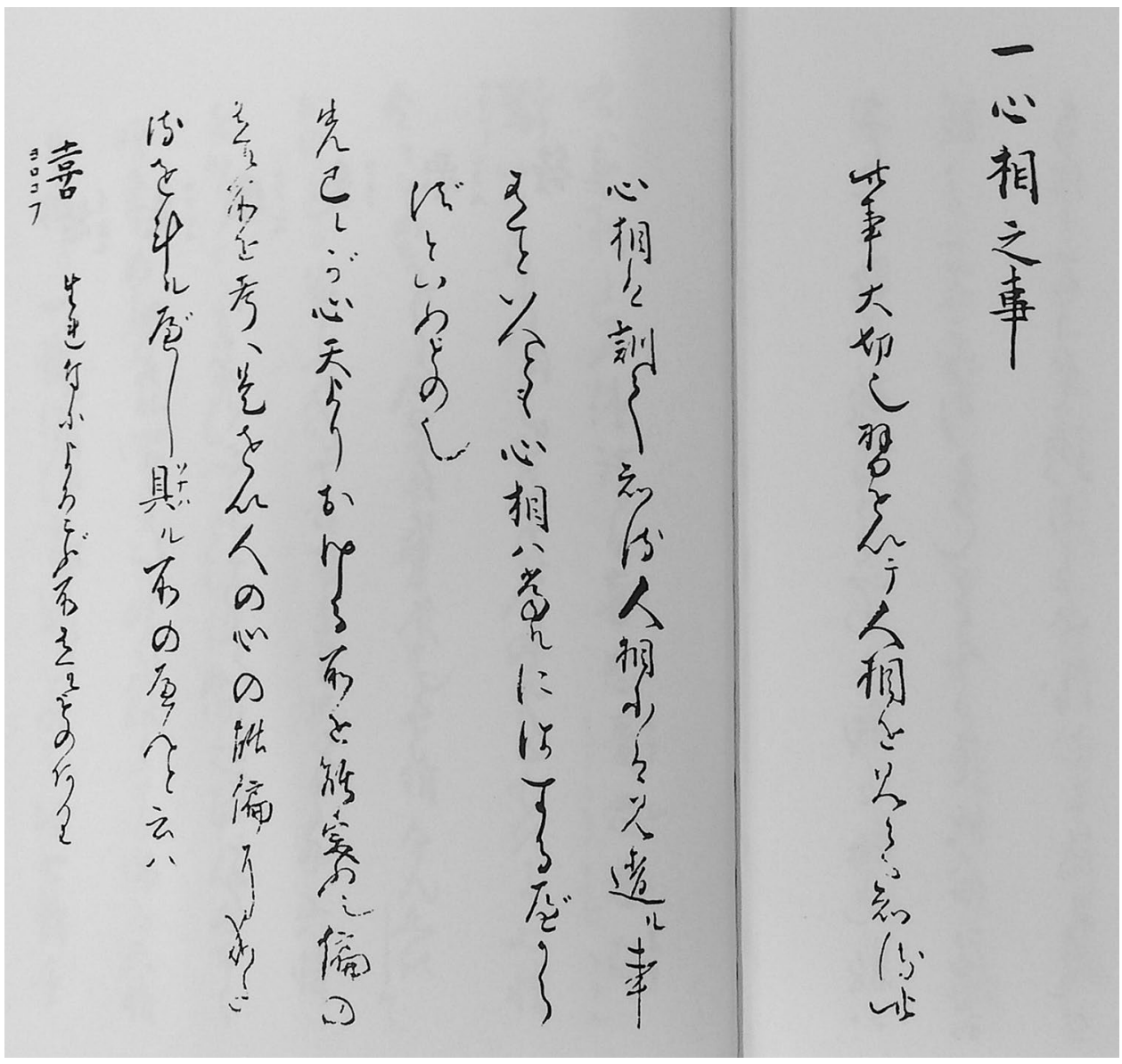

or following invasive therapeutic interventions, leading to injury to brain cells [14].

A limited number of studies have mentioned cognitive dysfunction after non-cardiac surgery. Most previous studies that utilized the neurological assessments used in cardiac surgery studies failed to detect any cognitive dysfunction after non-cardiac surgery. More recent studies have identified other factors associated with cognitive dysfunction, i.e., age, preoperative level of education and postoperative complications are listed as risk factors, while the effect of type of anesthesia may be minor [9, 15].

Advanced age is also an important risk factor for POCD $[10,11]$. Although cognitive dysfunction may occur regardless of the age of the patient, the dysfunctions seen at younger ages, when nervous systems are actively growing, should be considered separately from geriatric cases [16]. With advances in surgical technologies, invasive surgeries are more often performed on a progressively older and sicker population, who are at particular risk for cerebral injury during surgery [17]. Apart from aging or acquired diseases, congenital genetic variations, such as apolipoprotein genotype, have also been reported to affect susceptibility to injury as well as the ability to recover following injury [18, 19].
In a more recent clinical and epidemiological study, Dokkedal et al. surveyed 8,503 middle-aged and elderly twins to evaluate the effects of major surgery on cognitive functioning in later life. From the results of five cognitive analyses, they concluded that there was a negligible association between a history of major surgery and a lower level of cognitive function in later life [20]. Their supplementary analyses suggested that in mid- and late life, preoperative cognitive functioning and underlying diseases were more important determinants of POCD than surgery and anesthesia.

\section{Social impact of POCD and efforts for its prevention}

Although cognitive dysfunction may not be solely apparent by clinical observation, POCD is associated with impaired performance of activities of daily living. Cognitive dysfunction may also be associated with increased long-term morbidity or mortality, premature withdrawal from the labor market and social welfare transfer payments [15, 21].

Inouye et al. estimated that cognitive impairment complicates hospital stays for $>2.3$ million older people and 
Fig. 4 The number of publications regarding POCD available on 'PubMed' from 1975-2015

\section{Number of COPD relatied publications searched by PubMed}

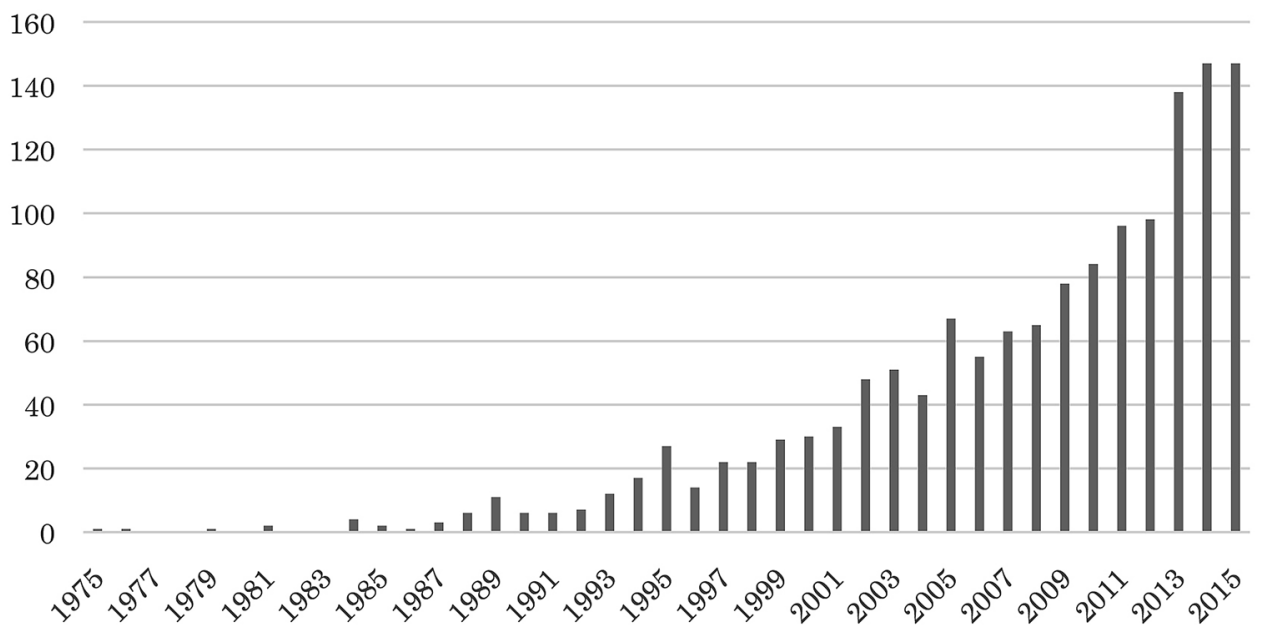

accounts for $>4$ billion dollars of Medicare expenditure in the United States each year. Substantial additional costs accrue after discharge from hospital, because of the increased need for institutionalization, rehabilitation and home care [22]. Hence, physicians should pay attention to brain protection perioperatively to improve the patient's quality of life postoperatively. A multidisciplinary approach must be developed to minimize the adverse effects of surgery on cognitive function, because deterioration in cognitive function has adverse societal consequences.

Compared to epidemiological and etiological descriptions, studies on the prevention and treatment of POCD are very limited. Several drugs, including aminophylline, haloperidol, donepezil and gabapentine have been evaluated and shown to have relatively minor ameliorating effects on cognitive impairment after general anesthesia [23-26]. Proper visual and hearing equipment, attention to preoperative pain, early mobilization, avoiding physical restraints, treatment of electrolyte imbalance and fluid deficit, ensuring normal sleep-awake cycles, and inclusion of family in the postoperative care plan, are other important factors in a smooth return to normal cognition after surgery [27].

\section{Journal of Anesthesia symposium 2016}

As mentioned above, the importance of adequate cognition throughout the perioperative period has been emphasized in developed countries, where the growing elderly population has increasing opportunities for invasive therapies, including surgery. In response to such a trend, the number of publications regarding POCD is also increasing annually (Fig. 4). The Journal of Anesthesia published 15 papers focusing on POCD from 2011-2015. POCD was selected as the main topic for the 2016 Journal of Anesthesia symposium. Five presenters presented their own most recent research outcomes and reviewed related publications. Takashi Kawano explained that postoperative delirium and POCD are closely related, and both are the result of an inflammatory reaction in the nervous system $[28,29]$. He also reported that postoperative pain management and intensive early rehabilitation seem to be important for the prevention of POCD in elderly patients. Kengo Maekawa showed that assessment of magnetic resonance images of the brain revealed reduced gray matter bilaterally in the medial temporal lobe, together with white matter lesions in the brains of elderly cardiac surgery patients who developed POCD [30, 31]. Kazuyoshi Ishida reviewed $>100$ previous studies and pointed out that many patients undergoing major vascular surgery under deep circulatory arrest or retrograde cerebral perfusion, and an equal or even larger number of patients undergoing surgery with selective cerebral perfusion, seem to develop POCD when compared with patients after coronary artery bypass grafting [32]. Koichi Suehiro stated that the duration of cerebral desaturation during single-lung ventilation (SLV) correlates with mini mental state examination scores, and that additional studies are needed to determine whether intervention against cerebral desaturation during SLV can prevent POCD [33, 34]. Shunsuke Tachibana reported that elderly patients receiving desflurane anesthesia have a significantly better quality of emergence and may have better cognitive function than elderly patients receiving sevoflurane anesthesia [35]. He suggested that transcriptome analysis of synaptic signal transduction might be a promising tool to explore the mechanism of POCD.

All of these presenters repeatedly indicated that the amount of reliable data is still limited, and that study 
protocols are extremely varied and non-standardized among previous POCD-related publications. Further wellorganized studies should be carried out to effectively prevent POCD, especially in developed countries, which have a large population of aged patients who are considered more prone to developing POCD.

\section{References}

1. Quirk R, editor. Longman dictionary of contemporary English. 3rd ed. Harlow: Pearson Education Limited; 2001. p. 250.

2. Taylor L, Watkins SL, Marshall H, Dascombe BJ, Foster J. The impact of different environmental conditions on cognitive function: a focused review. Front Physiol. 2016. doi:10.3389/ fphys.2015.00372.

3. Yokoyama S. Takedasingen to Kaisennoshou. Tokyo: Ebisukosyo-shuppan; 2011. p. 154-63.

4. Nicholas M. Manage your pain. London: Souvenir Press Ltd; 2008. p. 11-7.

5. Sekiguchi S. Chapter 9 in "Tendai shoshikan". Tokyo: Daitoshuppansha; 1978. p. 111-21.

6. Nakajima A. "Shoninki" by Fujinoissuishi M. Tokyo: Shinjinbutsuouraisha; 1996. p. 163-84 (original version in 1681).

7. Steinmetz J, Rasmussen LS. Peri-operative cognitive dysfunction and protection. Anaesthesia. 2016;71(Suppl 1):58-63.

8. Rudolph JL, Marcantonio ER. Review articles: postoperative delirium: acute change with long-term implications. Anesth Analg. 2011;112:1202-11.

9. Moller JT, Cluitmans P, Rasmussen LS, Houx P, Rasmussen H, Canet J, Jolles P, Larsen K, Hanning CD, Langeron O, Johnson T, Lauven PM, Kristensen PA, Biedler A, van Beem H, Fraidakis O, Silverstein JH, Beneken JE, Gravenstein JS. Long-term postoperative cognitive dysfunction in the elderly: ISPOCD1 study. Lancet. 1998;351:857-61.

10. Newman MF, Kirchner JL, Phillips-Bute B, Gaver V, Grocott H, Jones RH, Mark DB, Reves JG, Blumenthal JA. Longitudinal assessment of neurocognitive function after coronary-artery bypass surgery. N Engl J Med. 2001;344:395-402.

11. Sauer AM, Kalkman C, van Dijk D. Postoperative cognitive decline. J Anesth. 2009;23:256-9.

12. Grocott HP, Yoshitani K. Neuroprotection during cardiac surgery. J Anesth. 2007;21:367-77.

13. Jensen BO, Hughes P, Rasmussen LS, Pedersen PU, Steinbruchel DA. Cognitive outcomes in elderly high-risk patients after off-pump versus conventional coronary artery bypass grafting: a randomized trial. Circulation. 2006;113:2790-5.

14. Hudetz JA, Gandhi SD, Iqbal Z, Patterson KM, Pagel PS. Elevated postoperative inflammatory biomarkers are associated with short- and medium-term cognitive dysfunction after coronary artery surgery. J Anesth. 2011;25:1-9.

15. Monk TG, Weldon BC, Garvan CW, Dede DE, van der Aa MT, Heilman KM, Gravenstein JS. Predictors of cognitive dysfunction after major noncardiac surgery. Anesthesiology. 2008;108:18-30.

16. Fan Q, Cai Y, Chen K, Li W. Prognostic study of sevofluranebased general anesthesia on cognitive function in children. $\mathrm{J}$ Anesth. 2013;27:493-9.

17. Ito A, Goto T, Maekawa K, Baba T, Mishima Y, Ushijima K. Postoperative neurological complications and risk factors for pre-existing silent brain infarction in elderly patients undergoing coronary artery bypass grafting. J Anesth. 2012;26:405-11.

18. Ancelin ML, de Roquefeuil G, Scali J, Bonnel F, Adam JF, Cheminal JC, Cristol JP, Dupuy AM, Carrie`re I, Ritchie KJ.
Long-term post-operative cognitive decline in the elderly: the effects of anesthesia type, apolipoprotein E genotype, and clinical antecedents. J Alzheimers Dis. 2010;22(suppl 3):105-13.

19. Voigt Hansen M, Rasmussen LS, Jespersgaard C, Rosenberg J, Gogenur I. There is no association between the circadian clock gene HPER3 and cognitive dysfunction after noncardiac surgery. Anesth Analg. 2012;115:379-85.

20. Dokkedal U, Hansen TG, Rasmussen LS, Mengel-From J, Christensen K. Cognitive functioning after surgery in middle-aged and elderly Danish twins. Anesthesiology. 2016;124:312-21.

21. Steinmetz J, Christensen KB, Lund T, Lohse N, Rasmussen LS, ISPOCD Group. Long-term consequences of postoperative cognitive dysfunction. Anesthesiology. 2009;110:548-55.

22. Inouye SK, Bogardus ST, Charpentier PA, Leo-Summers L, Acampora D, Holford TR, Cooney LM. A multicomponent intervention to prevent delirium in hospitalized older patients. N Engl J Med. 1999;340:669-76.

23. El Tahan MR. Effects of aminophylline on cognitive recovery after sevoflurane anesthesia. J Anesth. 2011;25:648-56.

24. Kalisvaart KJ, de Jonghe JF, Bogaards MJ, Vreeswijk R, Egberts TC, Burger BJ, Eikelenboom P, van Gool WA. Haloperidol prophylaxis for elderly hip surgery patients at risk of delirium; a randomized placebo-controlled study. J Am Geriatr Soc. 2005;53:1658-66.

25. Sampson EL, Raven PR, Ndhlovu PN, Vallance A, Garlick N, Watts J, Blanchard MR, Bruce A, Blizard R, Ritchie CW. A randomized, double blind, placebo-controlled trial of donepezil hydrochloride (Aricept) for reducing the incidence of postoperative delirium after elective hip replacement. Int J Geriatr Psychiatry. 2007;22:343-9.

26. Leung JM, Sands LP, Rico M, Petersen KL, Rowbotham MC, Dahl JB, Ames C, Chou D, Weinstein P. Pilot clinical trial of gabapentin to decrease postoperative delirium in older patients. Neurology. 2006;67:1251-3.

27. Vaurio LE, Sands LP, Wang Y, Mullen EA, Leung JM. Postoperative delirium: the importance of pain and pain management. Anesth Analg. 2006;102:1267-73.

28. Kawano T, Morikawa A, Imori S, Waki S, Tamura T, Yamanaka D, Yamazaki F, Yokoyama M. Preventive effects of multisensory rehabilitation on development of cognitive dysfunction following systemic inflammation in aged rats. J Anesth. 2014;28:780-4.

29. Kawano T, Eguchi S, Iwata H, Tamura T, Kumagai N, Yokoyama $\mathrm{M}$. Impact of preoperative environmental enrichment on prevention of development of cognitive impairment following abdominal surgery in a rat model. Anesthesiology. 2015;123:160-70.

30. Maekawa K, Baba T, Otomo S, Morishita S, Tamura N. Low pre-existing gray matter volume in the medial temporal lobe and white matter lesions are associated with postoperative cognitive dysfunction after cardiac surgery. PLoS One. 2014;9:e87375.

31. Goto T, Maekawa K. Cerebral dysfunction after coronary artery bypass surgery. J Anesth. 2014;28:242-8.

32. Ishida K, Yamashita A, Uchida M, Matsumoto M. Development of postoperative cognitive dysfunction following major vascular surgery. Masui. 2014;63:1211-8.

33. Suehiro K, Tanaka K, Matsuura T, Funao T, Yamada T, Mori T, Nishikawa K. Discrepancy between superior vena cava oxygen saturation and mixed venous oxygen saturation can predict postoperative complications in cardiac surgery patients. J Cardiothorac Vasc Anesth. 2014;28:528-33.

34. Suehiro K, Okutai R. Duration of cerebral desaturation time during single-lung ventilation correlates with mini mental state examination score. J Anesth. 2011;25:345-9.

35. Tachibana S, Hayase T, Osuda M, Kazuma S, Yamakage M. Recovery of postoperative cognitive function in elderly patients after a long duration of desflurane anesthesia: a pilot study. J Anesth. 2015;29:627-30. 